\title{
Combining AHP with GIS for landfill site selection: Case of the Ben Ahmed circle
}

\author{
Ghizlane Benezzine ${ }^{1 *}$, Abdeljalil Zouhri ${ }^{1}$, and Yahya Koulali ${ }^{2}$ \\ ${ }^{1}$ Hassan First University of Settat, Faculty of Sciences and Techniques, Applied Chemistry and Environment Laboratory, Settat, \\ Morocco \\ ${ }^{2}$ Hassan First University of Settat, Faculty of Sciences and Techniques, Biochemistry, Neurosciences, Natural Resources and \\ Environment Laboratory, Settat, Morocco
}

\begin{abstract}
The demographic growth in the circle of Ben Ahmed leads to a large production of household waste. This waste is disposed of in uncontrolled open-air landfills. The informal discharge of this waste leads to negative impacts on the environment and on human health. To remedy these effects, this work aims to locate suitable locations for a sanitary landfill. The Analytical Hierarchy Process (AHP), a multi-criteria approach, and the Geographic Information System (GIS) were used. Following a thorough study, nine criteria were taken into account; distance to groundwater, water bodies, roads, highways, settlements, forests, land use map, elevation, and slope. Suitable sites have been identified to assist managers and officials in selecting a good location for a legal landfill.
\end{abstract}

\section{Introduction}

Solid waste management is a common problem, and the use of landfills is the most common method. The Moroccan population estimated at 33.8 million inhabitants in 2019, produces annually 6.85 million tons of household waste with 5.38 in urban areas, and 1.47 million tons in rural areas from National Program of Household Waste PNDM According to the Ministry of Environment [13]. The circle of Ben Ahmed is located in the North East of the province of Settat (Figure 1), with an area of 2450 hectares, and 220,535 inhabitants (HCP High Commission for the Plan 2014) [12]. The circle is composed of 20 communes that generate 102.2 tons/day of waste (Table 1) [1]. This waste is collected in uncontrolled landfills. Therefore, the present work aims at proposing suitable sites for the installation of controlled landfills to ensure good management of household solid waste and to minimize their negative impacts on the environment and public health[2], [3]. AHP An analytical prioritization process developed by Saaty in 1980 is the most widely used analytical decision-making technique for site selection in the world, this method is based on the weighting and combination of several criteria. Combined with a GIS geographic information system to establish a geographic database to extract a final map representing suitable sites for a controlled legal landfill [4]-[6].

Table 1. Quantity of waste generated [1]

\begin{tabular}{|c|c|c|}
\hline Communes & Population & $\begin{array}{c}\text { Tonnage } \\
\text { produced T/d }\end{array}$ \\
\hline Ben Ahmed & 32528 & 25,30 \\
\hline Oulad M'Rah & 8697 & 12,85 \\
\hline Sidi Hajjaj & 20732 & 6,25 \\
\hline Ras El Ain Chaouia & 14747 & 5,88 \\
\hline Sidi Abdelkrim & 14008 & 5,04 \\
\hline Oulad Fares & 12341 & 3,67 \\
\hline N'Khila & 12306 & 3,53 \\
\hline Mniaa & 11789 & 3,31 \\
\hline Sgamna & 10245 & 3,01 \\
\hline Oulad M'Hamed & 10187 & 3,10 \\
\hline Bouguargouh & 9539 & 2,90 \\
\hline Sidi Dahbi & 8703 & 2,55 \\
\hline Lakhzazra & 8582 & 2,48 \\
\hline M'Garto & 8514 & 2,56 \\
\hline Mrizigue & 8376 & 2,54 \\
\hline Ain Dorbane-Lahlaf & 8120 & 5,99 \\
\hline Oulad Chbana & 8081 & 2,55 \\
\hline Oued Naanaa & 6991 & 0,10 \\
\hline Loulad & 6049 & 8,59 \\
\hline Total & 220535 & 102,20 \\
\hline
\end{tabular}




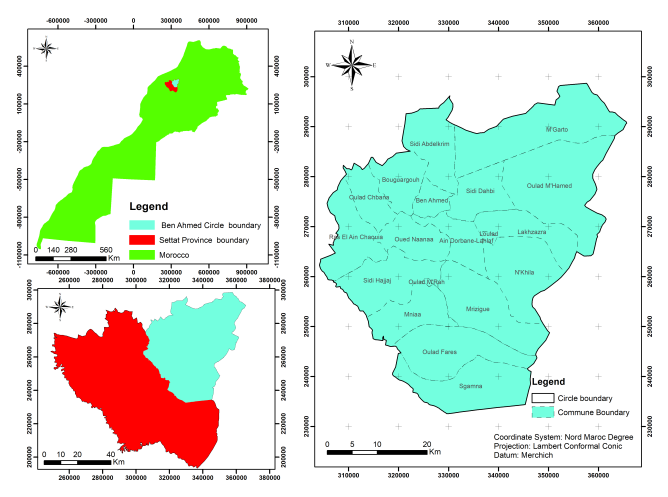

Fig. 1. Location of Ben Ahmed circle

\section{Materials and methods}

The choice of location of a legal landfill requires the respect of several environmental and economic criteria. Thus, a specific selection of sub-criteria (distance from; the ground water, Area water, roads ,highway, settlements, forests, land use map, elevation, and slope) (Figure2) was studied and analyzed via an AHP decision-making method[7]. For this, a pairwise comparison of the latter is essential. This comparison requires using a scale that varies from 1 to 9 . The least significant is assigned to 1 , while the most significant criterion is set to 9 (Table 2)[6], [8]. The second important step of the AHP is the calculating of weights (Table 3), then a consistency check of the peer comparison matrix is required [9]. this verification is done by a calculation of several indices via mathematical formulas: the consistency index (CI), the random index (RI), and the consistency ratio (CR). The final value of CR is significant if it is less than $0.1[10]$, [11]. A preparation and reclassification of the different maps collected used with ArcGIS software (GIS) are done via various tools. The integration of the resulting weights according to their importance to these maps is the last step. A final map is made specifying the least suitable and most suitable locations for installing the legal dump.
Table 2. Pairwise comparison scale [6]

\begin{tabular}{|c|c|}
\hline $\begin{array}{c}\text { Intensity of } \\
\text { importance }\end{array}$ & Definition \\
\hline 1 & Extremely less important \\
\hline 2 & Very strongly less important \\
\hline 3 & Strongly less important \\
\hline 4 & Moderately less important \\
\hline 5 & Equally important \\
\hline 6 & Moderately important \\
\hline 7 & Strongly important \\
\hline 8 & Demonstrate importance \\
\hline 9 & Extremely important \\
\hline
\end{tabular}

Table 3. Significance weights of main criteria and subcriteria

\begin{tabular}{|c|c|c|c|}
\hline Criteria & Weight & Sub- criteria & Weight \\
\hline \multirow{5}{*}{ 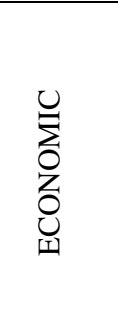 } & \multirow{5}{*}{$21 \%$} & Settlement & $5 \%$ \\
\hline & & High way & $3 \%$ \\
\hline & & Roads & $6 \%$ \\
\hline & & Elevation & $3 \%$ \\
\hline & & Slope & $4 \%$ \\
\hline \multirow{4}{*}{ 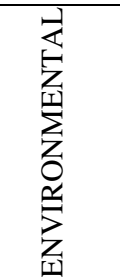 } & \multirow{4}{*}{$79 \%$} & Land use & $6 \%$ \\
\hline & & Forest & $15 \%$ \\
\hline & & Area water & $22 \%$ \\
\hline & & groundwater & $36 \%$ \\
\hline
\end{tabular}

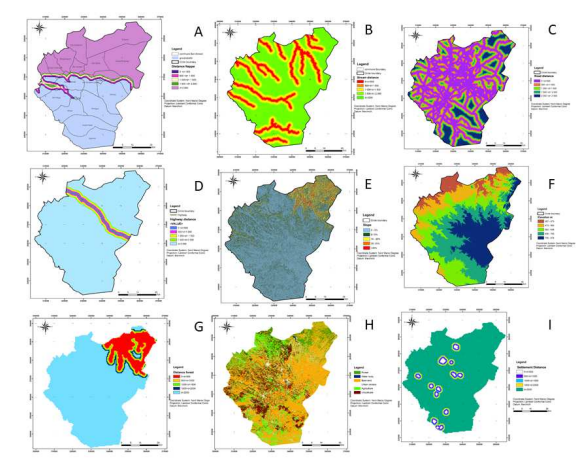

Fig. 2. Distance maps of; (A) groundwater, (B) Area water, (C) Roads, (D) High way, (E) Slope, (F) Elevation, (G) Forest, (H) Land use, (I) Settlement 


\section{Results}

The siting of a sanitary landfill must be subject to an evaluation process of criteria to prevent any long-term negative impact on the environment and human health, such as leachate's contamination of groundwater, surface water, and soil, besides pollution of air caused by odours or fumes. A final suitability map of the sanitary landfill of Ben Ahmed circle was made according to Moroccan standards (Figure 3), this landfill should be located far away from densely populated areas, water surfaces and groundwater; furthermore, low elevation and low slope, and a bare soil are the most suitable for less expensive landfill construction. In addition to that, the closest distance to roads $\mathrm{d}<500 \mathrm{~m}$ and the farthest distance from the highway $\mathrm{d}>2000 \mathrm{~m}$ are also important sub-criteria. The consistency ratio calculated is equal to $\mathrm{CR}=0.05<0.1$, which shows that the comparison is consistent.

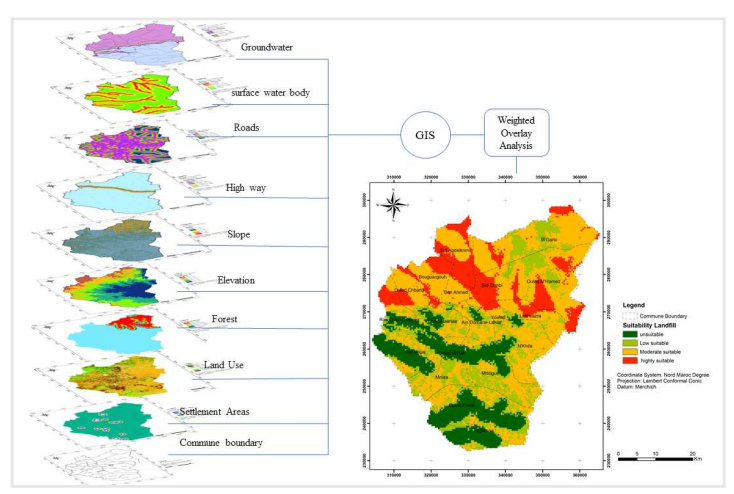

Fig. 3. Suitability map for landfill site selection

\section{Conclusion}

The siting of public sanitary landfills is an international and national challenge. In this work, a combination of an AHP decision support method and ArcGIS geographic information system software is used to select optimal sites for a landfill in the Ben Ahmed circle. For this, economic and environmental factors with nine sub-criteria are considered, studied, analyzed, and integrated into a GIS via ArcGIS software. The final map of the Ben Ahmed circle consisting of four classes will help the concerned authorities to decide the ideal location of the landfill.

\section{References}

1. G. Benezzine, Z. Abdeljalil, et K. Yahya, EEET, vol. 22, no 3, p. 1-10, (2021)

2. H. I. Mohammed, Z. Majid, et Y. B. Yamusa, IOP Conference Series: Earth and Environmental Science Vol. 220, No. 1, p. 012056. (2019)

3. J. Liu, Y. Li, B. Xiao, et J. Jiao, IJGI, vol. 10, $\mathbf{n}^{\mathbf{0}}$ 6, p. 403, (2021)

4. P. M. S. Abad, IJST 45(2), 1011-1030, (2021)
5. S. P. Gbanie, P. B. Tengbe, J. S. Momoh, J. Medo, et V. T. S. Kabba,AG, vol. 36, p. 3-12, (2013)

6. T. L. Saaty,EJOR, vol. 48, no 1, p. 9-26, (1990)

7. F. Elmahmoudi, O. E. Abra, O. Serrar, A. Raihani, L. Bahatti, et M. Rafik, 6th International Renewable and Sustainable Energy Conference (IRSEC), Rabat, Morocco, p. 1-7, (2018)

8. Ş. TÜdeş et K. B. Y. Kumlu, , IOP Conf. Ser.: Mater. Sci. Eng., vol. 245, p. 082063, (2017)

9. A. Chabuk, N. Al-Ansari, H. M. Hussain, S. Knutsson, et R. Pusch, WMR, Res, vol. 34, n 5, p. 427-437,(2016)

10. I.-S. Antonopoulos, G. Perkoulidis, D. Logothetis, et C. Karkanias,RCR, vol. 86, p. 149-159,(2014)

11. H. Ibrahim Mohammed, Z. Majid, N. Bin Yusof, et Y. Bello Yamusa, E3S Web Conf., vol. 34, p. 02010,(2018)

12. High Commission for the Plan https://www.hcp.ma/

13. Ministry of environment https://www.environnement.gov.ma/ 